\title{
Radiation-Induced Acoustic Cavitation; Apparatus and Some Results*
}

\author{
Martin Greenspan and Carl E. Tschiegg \\ National Bureau of Standards, Institute for Basic Standards, Washington, D.C. 20234
}

(August 22, 1967)

\begin{abstract}
Equipment and techniques for acoustic cavitation work are described. The test liquid and its container form part of a self-sustaining programmable oscillator. Emphasis is laid on the treatment of the liquid necessary to yield reproducible results after artificial nucleation, especially by neutrons, $\alpha$-recoils, and fission. With neutrons, for instance, the cavitation rate rises rapidly with acoustic (negative) pressure, and at fixed pressure is proportional to neutron flux. The cavitation events are random, and no appreciable induction or decay times are observed. Each cavitation arises from the action of a single neutron (or $\alpha$-recoil, or fission). The cavitation "threshold" (roughly negative pressure below which cavitation is rare) is highly variable from liquid to liquid. Thresholds at about room temperature for liquids irradiated with $10 \mathrm{MeV}$ neutrons ranged from 1 to 2 bars for $n$-pentane, ether, and freon 113 to over 50 bars for water.
\end{abstract}

Key Words: Acoustic cavitation, alpha-particle-induced cavitation, cavitation, cavitation nucleus, cavitation threshold, fission-induced cavitation, neutron-induced cavitation, radiationinduced cavitation, threshold.

\section{Introduction}

Our interest in cavitation research was aroused partly by the work of Lieberman [1959] but mostly by that of Sette and Wanderlingh [1962]. Also we felt that it would be desirable to develop techniques capable of yielding results more reproducible than those in the literature. Of course most investigators were aware that the day-to-day variability of their results reflected that of the population of nuclei in the liquid under test $;{ }^{1}$ indeed a cavitation experiment may be designed so that the results are best interpreted as a determination of the distribution of nuclei, a point emphasized by Messino, et al. [1963, 1967]. Still, we felt that some improvements in both apparatus and technique would be of value, and in this paper we describe what we have done so far and give some sample results which, although as yet uncoordinated by theory, illustrate how data of potential importance can be collected by relatively straightforward means.

We revert to the work of Lieberman [1959]. He was able to induce cavitation in acetone and pentane ${ }^{2}$ by neutron bombardment. The results, although very interesting and so far as they go in substantial agreement with those of the present work, were hardly surprising in view of what was then known about bubble chambers. The situation is different in the case of Sette and his co-workers [Sette and Wanderlingh, 1962; Messino, et al., 1963] and later, of Finch [1964] as well. Their results imply the existence, in water, of neutron-generated cavitation nuclei which have a long half-life, sometimes an hour or more.

\footnotetext{
*Work supported in part by the U.S. Office of Naval Research.

1 The disparity of results of various investigators reflects, in addition, the differences in experimental techniques and conditions, and in definitions of "threshold."

-Probably $n$-pentane.
}

The apparatus here described is suitable for determination of the following:

(1) Cavitation "thresholds" according to various arbitrary definitions.

(2) Cavitation-event rate as a function of pressure above threshold.

(3) Effect of static pressure.

(4) Influence of various nuclei, natural or artificial. The natural nuclei can be filtered out and replaced by others. Among these we emphasize those which are radiation-induced; by neutrons, by disintegration of dissolved $\alpha$-emitters, and by fission, both induced and spontaneous. In the case of neutrons, the prevailing view [Lieberman, 1959] is that the nucleation is connected with the deposition, in the liquid, of the kinetic energy acquired by an atomic nucleus of one of the heavier elements in the liquid as a result of an elastic collision with a neutron. In the case of $\alpha$-disintegration, the heavy recoil nucleus (a negative ion rather than a positive ion as in the previous case), is responsible, according to Riepe and Hahn [1961], who have examined this process in a bubble chamber.

So far our apparatus is not well adapted to studies of the effect of frequency.

For an overall view of acoustic cavitation the reader is referred to Flynn [1964] whose article contains 152 references.

\section{Apparatus, Major}

Other things being equal, cavitation occurs in that region of the liquid where the (negative) pressure is greatest; therefore it is necessary that the pressure at the walls of the container be substantially 
less than that in the "test" region, else cavitation will occur preferentially on the walls (or on the transducer, if it be immersed), and the results will not then represent properties of the liquid alone. ${ }^{3}$

In the case of traveling waves, they may be focused. Sette and W anderlingh [1962] used reflectors. The radiation from the concave side of a transducer which is the segment of a sphere is focused at the center; this arrangement was used by Willard [1953], and on a massive scale, by Sirotyuk [1962].

Standing-wave systems for the most part exploit the radial modes of a liquid-filled spherical flask, an arrangement devised by Leonard [1946] for another purpose and first adapted to cavitation work by Galloway [1954]. In such resonant systems the power requirement is just that needed to supply the losses; this advantage over traveling-wave systems is especially important where high sound pressures are required.

In our own work we use resonant systems, either cylinders or conical flasks.

\subsection{Cylinders}

The modes of vibration of a cylinder of fluid are well understood; here we give a brief treatment just to fix ideas. Modes that have an azimuthal dependence give zero pressure on the axis and maximum pressure on the walls; these are undesirable for our purpose and we consider radially symmetric modes only. The velocity potential, ignoring losses and with the time dependence exp $(i \omega t)$ suppressed, is

with

$$
\phi=J_{0}\left(k_{r} r\right)\left[A \cos k_{z} z+B \sin k_{z} z\right],
$$

$$
k^{2}=\omega^{2} / c^{2}=k_{r}^{2}+k_{z}^{2} ;
$$

the angular frequencies, $\omega$, are thus known in terms of the radial wave numbers, $k_{r}$, and the axial wave numbers, $k_{z}$, and the plane-wave speed of sound, $c$, in the liquid. The ratio $B / A$ depends on the impedance at the flat ends of the cylinder. Our practice is to use a thin sheet for the ends to make the impedance nearly zero; then with the origin at one end, and because the pressure is proportional to $\phi, A=0$ and $k_{z}=n \pi / L$, $L$ being the length of the cylinder and $n$ an integer. Equations (1) and (2) reduce to

$$
\phi=B J_{0}\left(k_{r} r\right) \sin (n \pi z / L)
$$

and

$$
k^{2}=\omega^{2} / c^{2}=k_{r}^{2}+n^{2} \pi^{2} / L^{2} .
$$

The pressure, radial velocity, and axial velocity are given by

$$
\begin{aligned}
p & =-i \omega \rho \phi, \\
u_{r} & =\partial \phi / \partial r=-B k_{r} J_{1}\left(k_{r} r\right) \sin (n \pi z / L),
\end{aligned}
$$

\footnotetext{
${ }^{3}$ Also, the apparatus may be damaged
}

and

$$
u_{z}={ }^{\prime} \partial \phi / \partial z=(B n \pi / L) J_{0}\left(k_{r} r\right) \cos (n \pi / L),
$$

respectively, with $\rho$ the undisturbed density of the liquid.

At $r=a$, the inside radius of the cylinder, the ratio $p / u_{r}$ must equal the radial driving-point impedance, $Z(\omega)$, at the wall. ${ }^{4}$. Then, with $k_{r} a=x$, we get from eq (5), (3), and (6)

$$
i \omega \rho a J_{0}(x) /(x) J_{1}(x)=Z(\omega),
$$

and from eq (4)

$$
(\omega / c)^{2}=(x / a)^{2}+(n \pi / L)^{2} .
$$

Equations (8) and (9) determine simultaneous values of $\omega$ and $x, Z(\omega)$ being supposed known. ${ }^{5}$

A difficulty common to all resonator systems is that the container must be pierced and provided with nilling tubes for introduction of the sample. These upset the sound field and also introduce losses. The above analysis shows that the tubes should be located either in the lateral walls near the ends or in the ends near the circumference. For at the positions $r=a, z=0$ or $L$, both the pressure, $p$, and the radial velocity, $u_{r}$, vanish [eq (5), (3), (6)]. As for the axial velocity, $u_{z}$, the ratio of its value at these positions to the maximum value is just $J_{0}(x)$ [eq (7)] which is also the ratio of the pressure on the lateral wall to that on the axis for any $z$. To prevent cavitation from occurring on the wall, $J_{0}(x)$ must be small-just how small depends on the smoothness of the wall. A "good" mode from this point of view therefore implies a relatively small disturbance at the filling tubes. Such modes are best found by trial; calculations from eq (8) and (9) are possible but tedious.

In the case of a spherical resonator all positions of the neck are equally bad. The experiences of Finch [1964] illustrate the point. These considerations, among others, impelled us to use cylinders instead of spheres. We will point out other advantages, and many disadvantages, as they come up. Just now we remark only that good geometry is easier to come by in a hollow cylinder than in a hollow sphere.

\section{a. Integral Drive}

Cylinders of piezoelectric ceramic are manufactured to close tolerances in a variety of sizes. We have used mostly $7.5 \mathrm{~cm}$ OD by 7.5 to $10 \mathrm{~cm}$ high and expect to try larger ones. As shown in figure 1 , the cylinder serves as part of the container, as the driving transducer, and as a pickup. It can be of lead-zirconate titanate or of barium titanate; in either case the material should be one especially formulated for low loss (internal heating) at high drive.

\footnotetext{
We here ignore the dependence of $Z(\omega)$ on $z$.

From these simple equations we have calculated the resonant frequencies of liquid filled cylinders and gotten good agreement with experiment. The pressure distributions, measured with a small probe, agree with those calculated, sometimes within a few percent.
} 


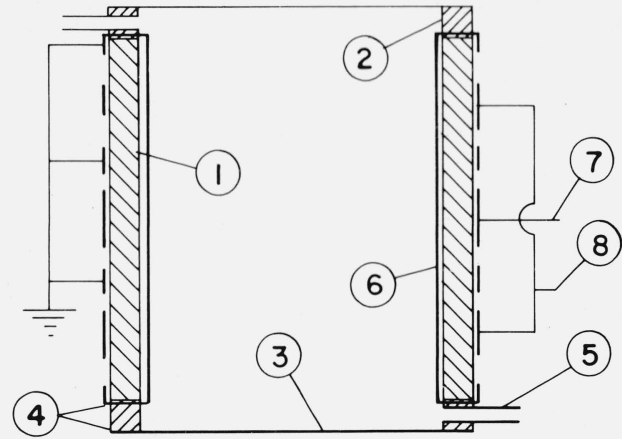

(a)

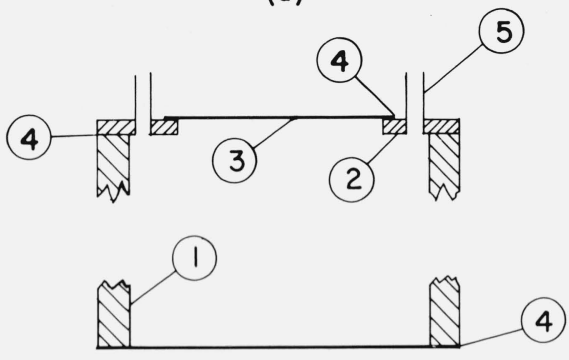

(b)

Figure 1. Self-driven cylinder, schematic cross section. (a) and (b), Alternate terminations and placement of filling tubes. The electrode config uration on (b) is the same as on (a).

1. Ceramic, either lead-zirconate titanate or barium titanate,

2. Metal rings, stainless steel or brass.

3. Sheet material, stainless steel or glass.

4. Cemented joints.

5. Filling tubes.

6. Electrode, around.

7. Electrode and connection, input.

8. Electrode and connection, output.

The metal rings allow for filling holes and connections. The flat ends are either stainless steel, 12 to 75 $\mu \mathrm{m}$ thick, or glass, $250 \mu \mathrm{m}$ thick. The glass, which is cut from microscope cover-glass stock, is fragile and difficult to handle, but it allows one to see what goes on. The thinner material provides a better pressure release than the thicker, but it is more easily excited (parametrically, we think) into radial flexural vibrations.

The joints shown in figure 1 are best cemented with a silicone-rubber adhesive which cures at room temperature. Many organic liquids attack this rubber, however; for these, some other adhesive, such as an epoxy, may serve. We have found no universal adhesive nor one which lasts indefinitely with any single liquid.

Manufacturers supply cylinders electroded on both the inside and outside with a fired-on silver-glass mixture. The outside electrode configuration shown in figure $l$ is produced by dividing the electrode as furnished and the inner ground electrode is connected with the outer ground bands by a conducting paint. In some cases we have removed the inner electrode and replaced and extended it over the edges with fired-on gold or platinum. ${ }^{6}$

These cylinders have two main limitations. The first, namely limited life of the adhesives, we have already mentioned. The second has to do with the roughness and friability of the inside walls. We would prefer to operate at the "breathing" mode $[(r, \theta, z)$ $=(1,0,1)]$ because the cylinder walls are for this mode more nearly pressure-release than for any other. Also, a larger fraction of the liquid is contained in the high-pressure region. However, unless the pressures are low, the wall motion in the $(1,0,1)$-mode is so large that the inside electrode (and sometimes the inner surface of the ceramic) disintegrates and contaminates the liquid. The overall performance is better in the $(3,0,1)$-mode and higher pressures are obtained. There is a tendency for cavitation to occur on rough spots on the wall, and this limits the maximum useful negative pressure obtainable to the range 20 to 30 bars, depending on the particular cylinder and the particular liquid. Such pressures are more than adequate for many organic liquids exposed to fast neutrons.

\section{b. External Drive}

"Clean" water exposed to fast neutrons cannot be cavitated in the ceramic cylinders described above. A special cylindrical vessel was fabricated from stainless steel tubing. The schematic, figure 2 , is mostly self explanatory.

The cylinder is operated in the $(3,0,1)$-mode, and the driver is adjusted to resonate at the same frequency at the temperature of test (in this case about $42.9 \mathrm{kHz}$ at about $30{ }^{\circ} \mathrm{C}$ ) in order to minimize the stress in the epoxy joint between the driver and a small milled flat on the cylinder.

${ }_{6}$ The cylinder is then repoled.

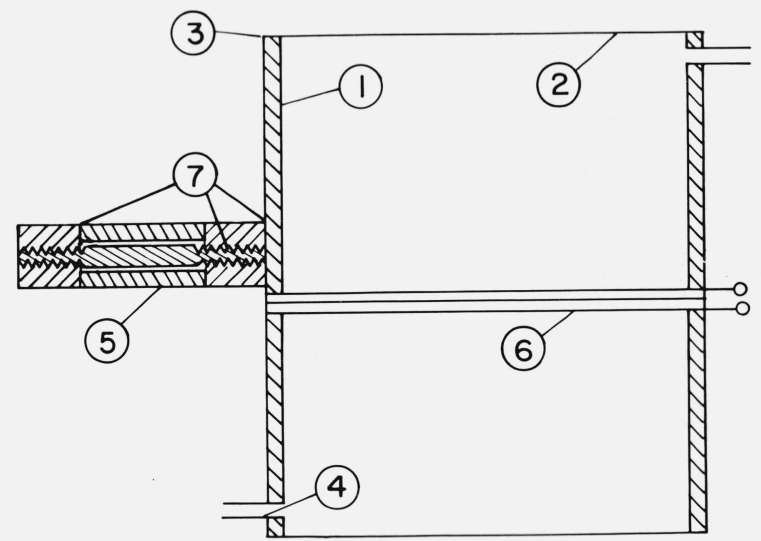

FiguRE 2. Externally driven cylinder, schematic cross section. 1. Stainless steel cylinder, $8.9 \mathrm{~cm}$ O.D. by $10.2 \mathrm{~cm}$ high, wall $0.16 \mathrm{~cm}$ thick. Inner surfaces polished

2. Stainless steel sheet, $75 \mu \mathrm{m}$ thick.

3. Silicone-rubber adhesive joints.

4. Filling tubes.

5. Composite, prestressed driving transducer, $13 \mathrm{~mm}$ O.D. The center section is lead zirconate-titanate: the ends and prestressing screw are of brass.

6. Wire strain gage.

7. Epoxy joints. 


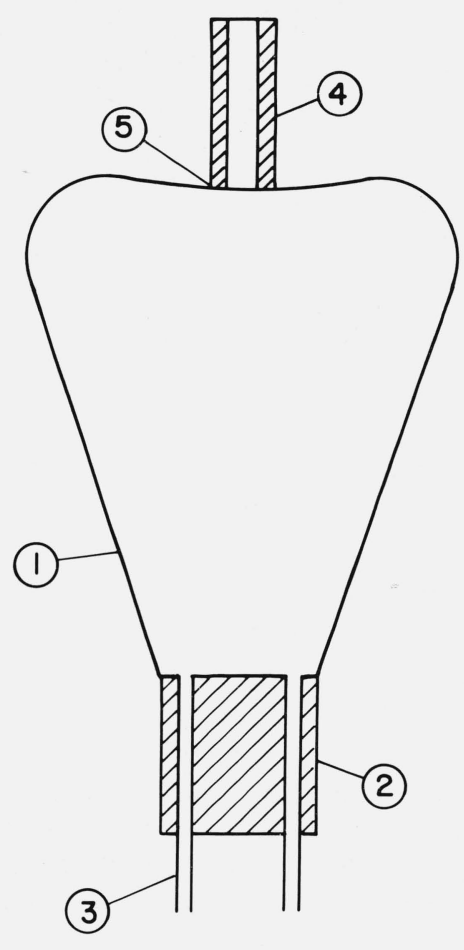

Figure 3. Conical flask.

Erlenmeyer flask, neck removed.

Solid glass plug with 2 holes.

Filling tubes.

Ceramic transducer

5. Epoxy joint.

At some temperature which fluctuates from day to day but is always within the range $29-31^{\circ} \mathrm{C}$, the overall $Q$ is a maximum at about 12000 . Negative pressures of 160 bars are sustained by the water for a minute or so at a time, and of 210 bars for a few seconds. The cavitations are presumed to be nucleated by either residual motes or adventitious neutrons.

The readout is from a wire strain gage noninductively wound around the circumference of the cylinder near midheight. It consists of three double turns of $75 \mu \mathrm{m}$ diameter Karma wire cemented into a double V. thread, $50 \mu \mathrm{m}$ deep, cut into the cylinder.

This cylinder could be used with various liquids and at various temperatures for work at low pressures; however, we have used it only for high pressures in water at one temperature. A change in temperature detunes the system and requires the transducer to be retuned. So far we have not found it worthwhile to do this.

\subsection{Conical Flasks}

Cylindrical geometry allows calculation of the pressure field and experimental verification (see footnote 5); this was one motivation for our choice. Nevertheless, we have made considerable use of the arrangement shown schematically in figure 3 for which these

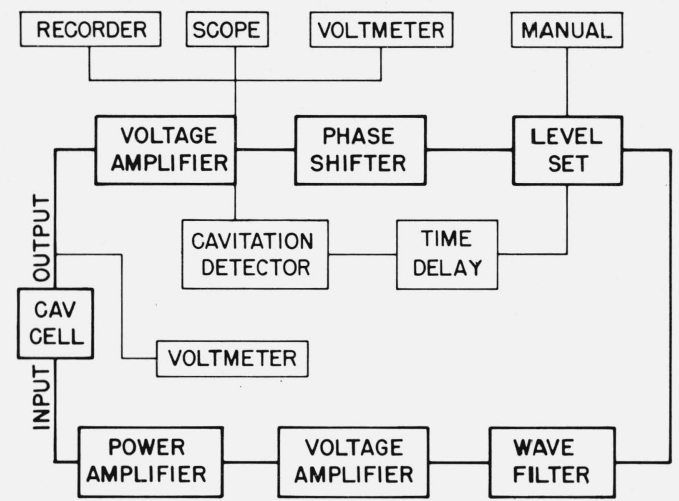

FIGURE 4. Circuit for use with cavitation cell. Schematic block diagram. The cell is the frequency-determining element of an oscillator.

advantages are absent. The container is made by replacing the neck of an ordinary Erlenmeyer flask $(125,250,300,500$, or $1000 \mathrm{ml})$ with a massive glass plug, typically about $25 \mathrm{~mm}$ OD by $25 \mathrm{~mm}$ long.

It was found empirically that each assembly has several modes for each of which there is a pressure maximum on axis and almost no motion in the plug. The flask can therefore be held by the plug without much loss of $Q$; the $Q$ may reach 10000 . The resonant frequencies and the $Q$ 's depend on the particular flask, transducer, liquid, and on the temperature, and cannot be predicted.

The advantages here are (a) that the vessel is of one-piece, all glass construction with no joints and (b) that the assemblies are cheap once the glassblower has taught himself how to eliminate rough spots on the inside. These advantages often outweigh the rather haphazard nature of the entire scheme, and we have collected a considerable amount of valuable data using it.

The drive is the voltage on, and the readout the current into, the transducer. See section 2.3.

\subsection{Electronics}

In all of our setups the cavitation cell, together with its associated reactive elements, such as transducers, is the frequency determining element of a self-sustaining oscillator. The scheme is shown in figure 4 . The wave filter, a simple combination of L,C-elements, is adjusted so that its pass band is roughly centered on the frequency of interest. For some setting of the phase shifter the system will oscillate at the desired frequency if the loop gain is large enough. Small changes in the resonance frequency of the cavitation cell, caused by temperature drifts, etc., are thus automatically tracked.

The amplitude of oscillation is adjusted to any desired value by variation of the supply voltage to a transistor stage ("level set" in fig. 4). The level can be set manually or programed in any desired way. 


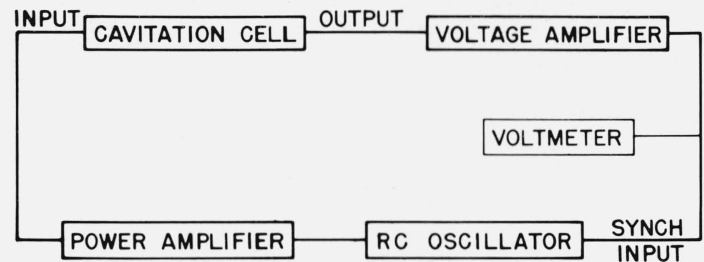

Figure 5. Circuit for use with cavitation cell. Variant featuring easy portability.

For instance, the pressure in the cell can be caused to increase linearly with time by application of a linear voltage ramp to the "level set."

The "cavitation detector" rectifies and differentiates the amplified output of the cell. A cavitation event drops the $Q$ of the system and therefore also the output amplitude; the resulting pulse can be made to trip a relay and interrupt the supply to the "level set," stopping the oscillation. The cavitation detector has adjustable sensitivity and can be made to trigger on mild events or on catastrophic events only. It can also be disabled. The rectified signal is amplified and applied to a small loudspeaker so that the cavitation events can be "heard."

After the relay has been tripped it can be reset after any desired elapsed time which exceeds the minimum delay set by the $Q$ of the system. Delays of $50 \mathrm{sec}$ or less are obtained from the sweep voltage available from the oscilloscope; longer delays are provided by a clock motor-switch arrangement.

The arrangement shown in figure 5 is not so versatile as the first, but is very simple and therefore well adapted to portable equipment. The amplified output synchronizes a Wien-bridge type oscillator. The oscillator functions as amplifier, filter, phase-shifter, and amplitude control (level set). The main disadvantage is that each time the amplitude is changed the frequency dial must be changed to restore the proper phase shift, for at a given setting of the frequency dial, the phase shift between the synchronizing and output voltages depends on the amplitude of the former [Owen, 1967]. A limiter at the synchronizing jack would perhaps improve the performance.

In all of the above, the term "cell output" refers to an electrical signal proportional to the maximum sound pressure in the liquid. In figure 1, the output is the voltage on the receiving bands (8). In figure 2 , it is the voltage across the strain gage (6) which has a resistance of $510 \mathrm{ohms}$, carries a bias of about $14 \mathrm{~mA}$, and is coupled to an amplifier through a 1 to 14 step-up transformer. The signal-to-noise ratio is poor so that filtering is necessary. In this case the amplifier is stagger-tuned; the 3 - $\mathrm{dB}$ bandwidth is about $2 \mathrm{kHz}$.

For the case of figure 3 , the input voltage is applied to the electrodes of the transducer; the output is the current into the transducer. As shown in figure 6, the current is sensed with a "clip-on probe," a common accessory for an oscilloscope. The probe measures the algebraic sum of the current to the transducer

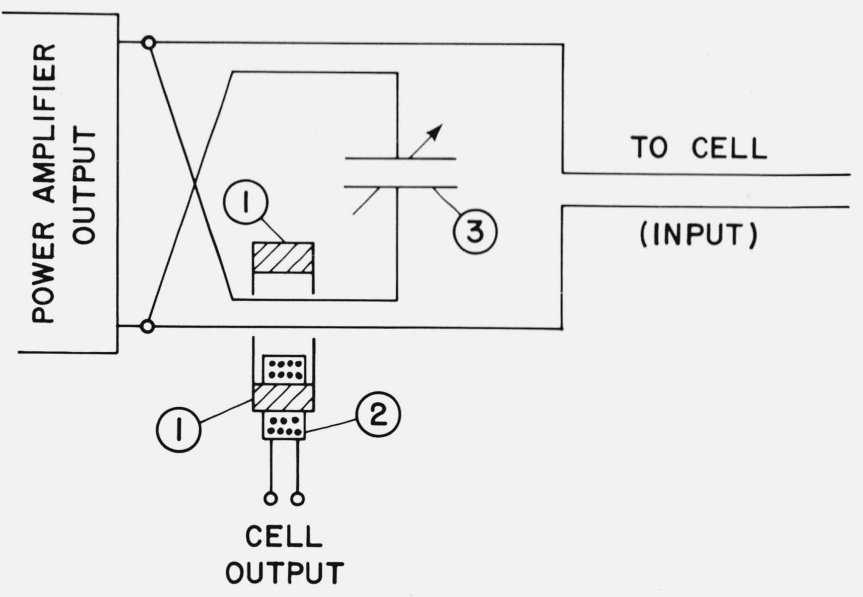

Figure 6. Output system for conical flask. Can also be used with the cylindrical cells of figures 1 and 2 . Especially convenient for
remote operation. The capacitance of $(3)$ is made equal to that of the leads plus that of the remote operation. The capacitance of (3) is made equal to that of the
transducer: the probe then responds to the motional current only.

and that to the capacitor (3) with its leads reversed. The capacitance of the auxiliary capacitor is made equal to the sum of the "free" electrostatic capacitance of the transducer and the capacitance of the leads; only the motional part of the current is measured. This arrangement makes it possible to have the cell a hundred meters or more from the rest of the equipment with only a single coaxial cable connection, provided that the power amplifier is capable of delivering the necessary in-quadrature current. Where a radiation hazard exists, this is a valuable feature.

\subsection{Calibration}

$$
\text { a. Probes }
$$

A principal object of a typical experiment is the determination of the maximum negative pressure in the liquid at the onset of cavitation. Those who work with spherical flasks usually make use of a probe microphone (probe). The active element is in most cases a small ceramic tube or disk; it is mounted on the end of a metal tube of diameter 1.5 to $3 \mathrm{~mm}$ which protrudes through the neck of the flask so that the active element is in a subsidiary pressure maximum. The designs are numerous; for a complete description of an especially clever one, see Barger [1964].

We have built many such probes, a few novel but none remarkable. In our work we find it essential not to have the probe in the liquid during test. Instead, the output of the cylinder is compared with the reading of a calibrated probe which passes through a small hole in the flat top of the cylinder during a separate run during which the sound pressures are not so great as to produce cavitation on the probe. Such a comparison has to be made for each liquid at each frequency and at each temperature. The procedure is tedious and in any case cannot be used in conical flasks. Also tedious is the calibration of the probe itself. For instance Barger [1964] employed a free-field reciprocity method, in water. We shall describe a novel method later on in this section. 


\section{b. Overpressure}

We describe a method of calibrating a cell, that is, of relating the sound pressure in the liquid to the reading of the output device, which is obvious but subject to some limitations. Suppose that under some specified condition a cavitation occurs at some negative pressure, $T$ (threshold, a positive number); then if $p_{s}$ is the static, and $p_{1}$ the amplitude of the acoustic, pressure,

$$
T=p_{a}-p_{s}
$$

The output is some voltage $V$, supposed proportional to $p_{a}$, so that eq $(10)$ is

$$
V=\left(p_{s}+T\right) / m,
$$

in which $p_{a}=\mathrm{mV}$. Two measurements of $V$ for two values of $p_{s}$ determine $T$ and $m$. The method fails if $T$ depends on $p_{s}$. For instance, if the cavitation nucleus is a gas or vapor bubble, somehow stabilized at (say) atmospheric pressure against dissolution or condensation, respectively, then an increase in the static pressure $p_{s}$ will shrink the bubble and the liquid will be "strengthened," i.e., T will change with $p_{s}$ so that eq (10) is no longer linear. This phenomenon has been discussed by Strasberg [1959].

On the other hand, we find that if the cavitation is induced by neutron bombardment or $\alpha$-disintegration, then the threshold, $T$, is independent of the static pressure $p_{s}$. The cell is enclosed in a pressure vessel and the output, $V$, at threshold is determined for various values of $p_{s}$. A plot of $V$ as ordinate versus $p_{s}$ as abscissa yields a straight line, of which the $p_{s^{-}}$ intercept, with reversed sign, is the threshold, $T$. There is no measureable hysteresis. In practice, $T$ is calculated from the data by least squares. The vessel is pressurized with nitrogen and the value of $p_{s}$ read on a high-quality bourdon-tube gage. A piston arrangement (actually a hypodermic syringe) transmits the pressure to the liquid, as will be described later.

A major advantage of this "over-pressure" method is that the nature of the pressure field in the cell does not need to be known.

\section{c. Calibration of Probes}

As a byproduct, the overpressure method provides a simple way of calibrating the small, rather insensitive probes already discussed.

Some threshold, $T$, which as always has an arbitrary definition, but which must be reproducible, is measured by the overpressure method in a cylindrical cell such as shown in figure 1 . The maximum acoustic pressure amplitude (at the center of the cell) is now known in terms of the output voltage. A probe inserted through a small hole in the top is then easily calibrated against the output voltage; the result applies at the frequency of test only. Other frequencies may be gotten by changes of mode and/or liquid. For probes which are sensitive on the flat end only, the response may be extended over any frequency range by means of an electrostatic actuator. ${ }^{7}$

\section{Apparatus, Auxiliary}

\subsection{Cleanup of Liquid}

The exact nature of the natural nuclei in liquids is unknown and almost certainly variable from sample to sample and from time to time. Presumably they are either bubbles (gas or vapor) somehow stabilized upon motes or motes which are poorly wetted; in any case those larger than a specified size can be removed by filtration. Membrane filters of large area, with uniform pores and relatively large flow rates are long since a common article of commerce. General purpose types have a pore size as small as $0.01 \mu \mathrm{m}$. These are attacked by some organic liquids; for many of these, other types having a pore size as small as $0.2 \mu \mathrm{m}$ are available.

The degree of cleanup required depends on the nature of the case. For instance, suppose one wishes to measure some cavitation threshold, $T_{1}$, under irradiation by neutrons from a particular source. Then it is necessary, in order to get reproducible results, to remove from the liquid all nuclei upon which cavitation can occur at stresses less than about $2 T_{1}$. Because the rate of flow of a liquid through a filter is smaller the smaller the pore size, a cleanup more drastic than necessary is undesirable.

In these respects, so far at least as $T_{1}$ is concerned, the most refractory liquid, among those we have so far tried, is water. If all motes retained by a filter of pore size $0.2 \mu \mathrm{m}$ are removed, water will sustain negative pressures in excess of 200 bar for a short time, and of 100 bar almost indefinitely, so that conditions are satisfactory for the determination of a value of $T_{1}$ near 50 bar. However, it does not suffice merely to pour distilled water through a filter into the test container, for the latter contains dirty air; even if it is first evacuated, the water will become contaminated by material on the walls. Rather it is necessary to make use of a scheme equivalent to that shown in figure 7 . After the assembly shown is filled, the valves (2) may be set to form a closed system so that the water can be continuously circulated by a bellows or diaphragm pump. Alternatively, if a still is available which can produce water as fast as it flows through the filter, the pump can be dispensed with and the valves (2) set to admit and discard the water continuously. The cleanup time is greatly shortened by acoustic agitation of the cell during the procedure and by the addition of detergent to the inflowing water during the early stages. The progress of the cleanup can be observed through a dark-field microscope focused on the effluent in a piece of precision-bore rectangular glass tubing,

${ }^{7}$ The electrostatic actuator of Ballantine [1932] is described by Beranek [1949], p. 173 In our case it is not feasible to use it as an absolute device. 


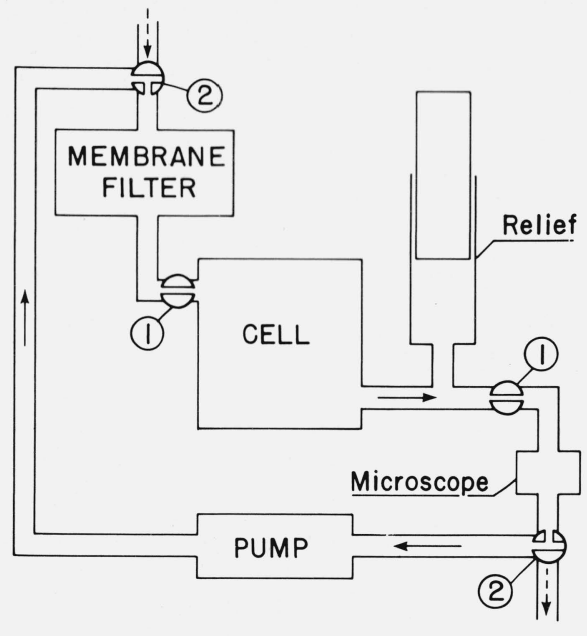

Figure 7. Cleanup system, schematic. Some of the components are used only in special cases. $1,2=$ valves

optically finished on the outside. The microscope arrangement is rather crude, but it works well so long as the effluent is still rather dirty; however the field of view is so small that after a few minutes of operation the waiting time for passage of a mote becomes long enough to fatigue the observer and render his perception unreliable. Its main virtue is that it makes it possible to determine whether or not the shock wave caused by the collapse of a cavitation bubble has dislodged additional motes from the wall. In the case of water in a stainless steel cell, such dislodgment happens almost invariably, so that meaningful observations can be taken only at long intervals, say 5 to $15 \mathrm{~min}$.

A much less stringent procedure is required for organic liquids, at least the dozen or so we have so far used. Two possible reasons come to mind; first, the thresholds, $T_{1}$, are lower than for water and second, the motes are either better wetted by, or more soluble in the organics. Whatever the reasons, it turns out that $T_{1}$ is, in all cases so far, easily measured after only 10 or so minutes of circulation in an apparatus like that in figure 7. (The microscope is omitted.) Valves (1) are then closed and the connecting tubes detached so that the cell and relief element can be removed for use. The relief element, which is a hypodermic syringe, maintains the ambient pressure, or the overpressure, on the contents.

For some liquids pouring or pumping through a filter into the flask, previously cleaned and rinsed with the liquid, is sufficient. In others, even the filtering may be omitted, especially if the sample is from a freshly opened bottle.

\subsection{Gas Content of Liquid}

Under some circumstances the cavitation threshold is sensitive to the gas tension in the liquid. This tension can be adjusted by allowing the liquid to come into

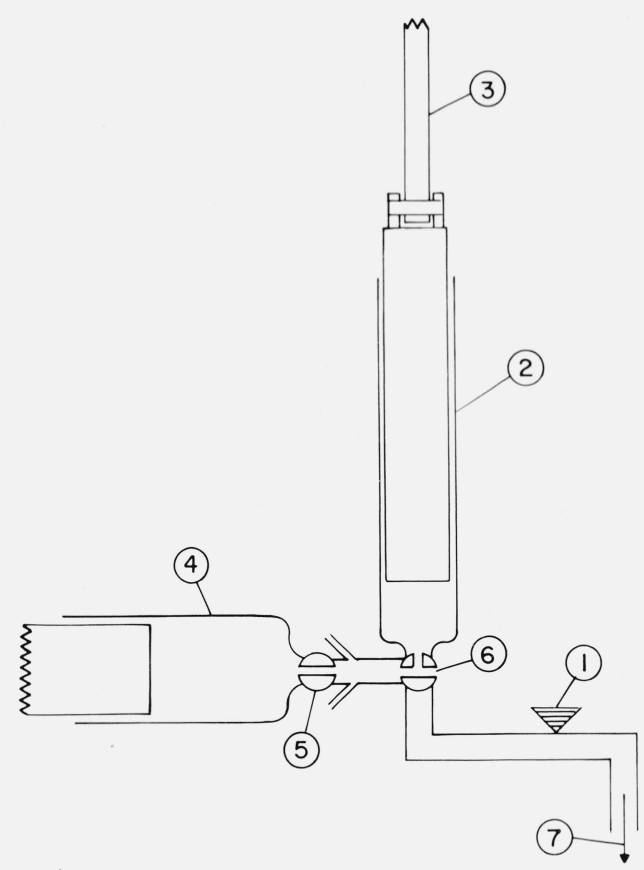

FiguRE 8. Apparatus for determination of oxygen, schematic.

1. Sensor, active tip in liquid.
2. Metering syringe, $5 \mathrm{~cm}^{3}$ Luerlok hypodermic.

Metering syringe, $5 \mathrm{~cm}^{3}$ Luerlok hypodermic.
Rack, hinged to plunger, engages pinion (not shown) on clock motor (not shown).

Sample or standard syringe, $10 \mathrm{~cm}^{3}$ Luerlok hypodermic.

Stopcock, one-way, attached to syringe (4).

Stopcock, 3-way, attached to syringe (2).

Waste

equilibrium with a gas at a partial pressure which is itself adjusted. For example, a liquid is easily saturated by bubbling the gas through it at the particular temperature and pressure for which saturation is desired. Also most of the dissolved gas can readily be removed by pumping on the space above the liquid in a closed container while stirring violently. A combination magnetic stirrer and hot plate is invaluable for this purpose.

The gas tension may be measured by any of several methods known to physical chemists. Strasberg [1959], and others since, made use of a Van Slyke blood-gas apparatus, available from chemical supply houses. If the gas is air, which is usually the case, 8 one can use techniques peculiar to oxygen. We have found a polarographic technique based on the oxygen cathode to be very convenient. For a comprehensive review see Davies [1962]. We describe only the modifications peculiar to our work.

In figure $8,(1)$ represents a sensor, about $1 \mathrm{~mm}$ in diameter, which is embedded in the wall of a tube about $3 \mathrm{~mm}$ in diameter past which the test liquid flows. The sensor has a current output (a few microamperes) which is proportional to the rate at which $\mathrm{O}_{2}$ is reduced on an inert (gold, in our case) cathode separated from the test liquid by a thin film of electrolyte and a teflon

\footnotetext{
${ }^{*}$ An exception is the study of sonoluminescence which is sensitive to the nature of the dissolved gas.
} 
membrane. The $\mathrm{O}_{2}$ reaches the cathode by diffusion through the membrane so that the output current is proportional to the concentration of $\mathrm{O}_{2}$ just outside it. The electrolysis depletes the liquid of $\mathrm{O}_{2}$, so that the current output depends on the speed of flow in the tube. The device shown in figure 8 standardizes the flow rate and allows compensation for other variables to be described. But first we note that the sensor, which is a modification of the "Clark cell" is easily made. Ours is a modification of a commercial model. The original $\mathrm{Ag}$ anode has been replaced by $\mathrm{Ag}-\mathrm{Ag}_{2} \mathrm{O}$, and instead of a $\mathrm{KCl}$ gel we use, as electrolyte, $0.5 \mathrm{~N}$ $\mathrm{KOH}$ saturated with $\mathrm{Ag}_{2} \mathrm{O}$ and thickened with hydroxyethyl cellulose. This arrangement is more stable and has a longer life than the original; it is based on the work of Connelly and of Carrit and Kanwisher [see Davies, 1962, p. 172].

The metering syringe in figure 8 is driven by a clock motor through a rack and pinion; the flow is $5 \mathrm{~cm}^{3} / \mathrm{min}$ which amounts to about $2 \mathrm{~cm} / \mathrm{s}$ past the sensor. Before making a measurement, a sample is withdrawn from the apparatus into a $10-\mathrm{cm}^{3}$ syringe provided with a stopcock (5), taking the usual precautions to exclude air. At the same time a sample is withdrawn into another, similar syringe from a bottle of the same liquid in the oven and thus at the same temperature as the test sample. This "standardizing" liquid is maintained saturated with air at the temperature of the oven and the pressure of the atmosphere. In each case the first withdrawal is discarded so that the syringe is purged of air and residual liquid. The two syringes, "standard" and "sample" with stopcocks (5) closed are then allowed to come into temperature equilibrium with the ambient at the location of the apparatus in figure 8; the contents are then successively run through. The ratio of the "sample" reading to the "standard" reading gives the oxygen tension in percent relative to saturation at 1 atm total air pressure. Before taking a reading, the metering syringe and associated tubing are purged with "test" or "standard" liquid by an obvious manipulation of the stopcocks; the rack is hinged so that it can be lifted from the pinion to allow hand operation which facilitates the process. The output current reaches a steady value after about $1 \mathrm{~cm}^{3}$ of liquid has been expelled.

It will be seen that the scheme described eliminates all of the important sources of error. These are (a) changes due to changes in flow rate past sensor, (b) drifts due to aging of the cell, and (c) changes in sensitivity which arise from the high temperature coefficients of diffusion in the liquid and in the Teflon.

\subsection{Radiation Sources}

As was mentioned in the introduction, cavitation has been induced by neutron bombardment, by $\alpha$-disintegration, and by fission.

\section{a. Neutrons}

Most of the work so far done has been with $(\alpha, n)$ sources. In all cases the target atom has been $\mathrm{Be}^{9}$ : the $\alpha$ emitters have been Ra [Sette and Wanderlingh, 1962], $\mathrm{Po}^{210}$ [Lieberman, 1959], $\mathrm{Am}^{241}$, and $\mathrm{Pu}^{239}$ [Hahn and Peacock, 1963]. The main disadvantage of a Ra source is its high $\gamma$-ray background, about 6500 $\gamma$ 's/neutron. A Po source is small, but has a short half-life (138 days). Of those sourcés we have had an opportunity to use, the best from the standpoint of size, half-life, and safety is Am-Be. The Pu-Be source is about as good but larger; we now use $\mathrm{Pu}$-Be because of its lower price.

The characteristics of $(\alpha, n)$ sources are listed in NBS Handbook 72. The neutron energy spectra of such sources are variable even among those nominally the same, and they are known only approximately. The energy varies from zero to a maximum of 13.1, 10.9, 11.4, and 10.7 MeV for Ra, Po, Am, and Pu, respectively, and the average energy is about $4.5 \mathrm{MeV}$.

Most of our work has been done with a 10-curie $\left(\begin{array}{l}160 \mathrm{~g} \\ \mathrm{Pu}\end{array}\right) \mathrm{Pu}-\mathrm{Be}$ source having a total output of $1.47 \times 10^{7} \mathrm{n} / \mathrm{s}$.

The data would be more easily interpreted if the more nearly monoergic neutrons produced by particle accelerators were used. Finch [1964] worked with $14 \mathrm{MeV}$ neutrons produced by the $[\mathrm{T}(\mathrm{d}, \alpha) n]$ reaction. We have made a few runs using this and also the $\left[D(d, n) \mathrm{He}^{3}\right]$ reaction $(2.5 \mathrm{MeV}$ neutrons), but the neutron fluxes were rather unsteady.

\section{b. $\alpha$-Disintegrafion}

The short range of the heavy recoil nuclei from disintegration of a dissolved $\alpha$-emitter is a valuable property; the cavitation data are more easily interpreted. In order that the dissolved emitter not affect the properties of the liquid too much, it should have a high activity, so that only traces are required. $\mathrm{Po}^{210}$ perhaps represents a good compromise between high activity and reasonable half-life; we have not yet tried it for lack of facilities for safe handling. A possible difficulty is that for some liquids too much of the Po compound may be adsorbed on the walls of the container, leaving too little in the bulk of the liquid.

Ordinary thorium nitrate, $\mathrm{Th}\left(\mathrm{NO}_{3}\right)_{4} \cdot 4 \mathrm{H}_{2} \mathrm{O}$ is soluble in the lower alcohols and ethyl ether. We have used concentrations of 1 to $10 \mathrm{~g}(\mathrm{Th})$ per liter in methyl, ethyl and isopropyl alcohol with good results. Uranyl nitrate $\mathrm{UO}_{2}\left(\mathrm{NO}_{3}\right)_{2} \cdot 6 \mathrm{H}_{2} \mathrm{O}$, is also soluble in these liquids. Although about three times as active as thorium, uranium is not as well suited to this work because of the high spontaneous fission rate ${ }^{9}$ of $\mathrm{U}^{238}$.

It should be remembered that laboratory reagent grades of thorium and uranium salts are contaminated with daughter products, many of which are $\alpha$-emitters.

Cavitation occurs at relatively low stresses on fission events in liquids. Any salt of the fissionable material, soluble in the liquid, may be used. Slow, fast, and spontaneous fission have been observed.

\footnotetext{
${ }_{9}^{4}$ About $25 \mathrm{n} / \mathrm{g}$ hr. For $\mathrm{Th}^{232},<0.15 \mathrm{n} / \mathrm{g} \mathrm{hr}$.
} 
Cosmic-ray neutrons are a potential source of cavitation nuclei and should be reckoned with under some circumstances. Watt [1967] has reviewed some of the literature; as an average he takes the total flux density to be $65 \mathrm{n} / \mathrm{cm}^{2} / \mathrm{hr}$ at sea level in the middle latitudes. Of the total, most have low energies and only 7 percent $\left(4.5 \mathrm{n} / \mathrm{cm}^{2} / \mathrm{hr}\right.$, are above $10 \mathrm{MeV}$. Recent measurements by Tajima, et al. [1967], indicate a much lower flux density, at least in the range $2-10$ $\mathrm{MeV}$, and an altitude dependence like $\exp (-0.0063 x)$, $x$ being the atmospheric depth in $\mathrm{g} / \mathrm{cm}^{2}$.

In total flux density, the cosmic-neutron background is equivalent to the neutron source in our laboratory $\left(1.47 \times 10^{7} \mathrm{n} / \mathrm{s}\right.$ into $\left.4 \pi\right)$ at a distance exceeding 80 meters, and the former has a smaller fraction of neutrons at the higher energies.

\section{Some Results}

\subsection{General}

To fix ideas, we consider water at atmospheric pressure. The frequency of the sound pressure is in the range $25-50 \mathrm{kHz}$ and as a threshold we take the negative pressure at which the average waiting time for cavitation is (say) $30 \mathrm{sec}$. The threshold in ordinary tap water or in distilled water, both of which contain numerous motes, varies markedly with the amount of dissolved air, being higher the less air; furthermore the threshold is variable from sample to sample and from time to time in the same sample. Values range from 1 bar or less at saturation (with air) to perhaps 10 bars at 10 to 30 percent saturation. Barger [1964] studied these effects for a wide range of many of the variables and Messino et al. [1967], added to the water both wettable and unwettable motes; their results well illustrate the possibilities.

We have found the situation to be different, however, if the water is cleaned up taking the precautions described in section 3.1. In this case the threshold rises as more of the motes are removed, no matter what the air content, so long as it is below saturation [Greenspan and Tschiegg, 1966a, b]. It seems that no important purpose is served by protracted cleanup; the threshold continues to rise unless (presumably) the experiment is terminated by an adventitious neutron.

Table 1 summarizes a few results from the literature. The three sets are not strictly comparable although Finch duplicated Galloway's apparatus so far as possible. Note the marked effect of the amount of dissolved air.

Our measurements were taken at $43 \mathrm{kHz}$. At 46 $\mathrm{kHz}$, Barger [1964] reports thresholds ranging from 1.2 bar at 760 torr partial pressure of air to 12.1 bar at 10 torr. These contrast with our thresholds of about 160 bar (several minute basis) or 210 bar (several second basis) independent of air content from 120650 torr. Presumably the air content has less effect the cleaner the water.

\begin{tabular}{|c|c|c|c|c|c|}
\hline & \multicolumn{5}{|c|}{ Threshold, ${ }^{a}$ bar } \\
\hline & \multicolumn{5}{|c|}{ Partial pressure of dissolved air, torr. } \\
\hline & 0.2 & 4 & 100 & 250 & 700 \\
\hline $\begin{array}{l}\text { Galloway [1954] b, c. } \\
\text { Barger }[1964]^{\mathrm{e}} \ldots \ldots \ldots\end{array}$ & $200^{d}$ & 110 & \multirow[t]{2}{*}{$\begin{array}{l}8 \\
8\end{array}$} & \multirow[t]{2}{*}{$\begin{array}{l}3 \\
3\end{array}$} & \multirow[t]{2}{*}{$\begin{array}{r}1.1 \\
.70\end{array}$} \\
\hline Finch $[1964] \ldots \ldots \ldots . . . .$. & & $9 \pm 3^{f}$ & & & \\
\hline
\end{tabular}

a Sound pressure amplitudes; static pressure 1 bar. The three threshold definitions are roughly equivalent. Frequency $\sim 26$ $\mathrm{kHz}$.

b Interpolated from a curve.

c Spread about \pm 12 percent.

d According to a private communication, Galloway to Finch [1964] high value gotten sporadically. More often 15 to 20 bars. e Spread not given.

${ }^{f}$ Another mode of operation gave 50 to 80 bars.

\subsection{Neutron-Induced Cavitation}

This effect was first found in acetone and in pentane by Lieberman [1959]. We have observed it since in water, isopropanol, and freon $113\left(\mathrm{~F}_{2} \mathrm{ClCCCl}_{2} \mathrm{~F}\right)$ [Greenspan and Tschiegg, 1966a], in ethanol [Greenspan and Tschiegg, 1966b] and later in another dozen or so organic liquids.

Two results stand out. First, the air content of the liquid affects the threshold little if at all. Lieberman also found this. Second, there is no appreciable induction or decay time for the effect. West and Howlett [1967] have since investigated this point in detail; in the liquid they used, tetrachloroethylene, the lifetime of a bubble is about $2 \mu \mathrm{s}$. These results were obtained in an elegant experiment using a pulsed neutron source. We have already alluded to the results of Finch [1964] and of Sette's group, which contrast markedly with, e.g., ours. They find a cumulative effect; many minutes or even an hour of exposure to neutrons are required to "weaken" the liquid (water in both cases) and the "strength" returns at a similar interval after exposure is terminated. Sette and his co-workers [Bertolotti et al. 1965, p. 109] feel that long lifetimes are characteristic of gassy (i.e., saturated with air at the static pressure) water; however Finch's water, which showed the effect, was only 0.5 percent saturated, and our water does not show the effect even if gassy. Perhaps dirt is more important than gas.

\section{a. Statistics}

The question which obtrudes itself most forcefully is whether or not the cavitations are single-particle events, that is, whether each cavitation is traceable to a single neutron or whether each is due to the cooperative effect of two or more neutrons. In the former case the cavitation rate would (a) follow a 
Poisson distribution, and (b) satisfy the inverse-square law for various distances of the neutron source from the cavitation cell.

Lieberman's [1959] results in pentane were "reasonably close to a Poisson distribution." We have investigated this point in detail; the test liquid was isopropanol (table 2). Two independent runs were made using the $(3,0,1)$-mode of a lead zirconate titanate cylinder of the type shown in figure l(a). The temperature in each case was about $31{ }^{\circ} \mathrm{C}$ and the frequency about $40 \mathrm{kHz}$. An Am-Be source radiating $1.6 \times 10^{7} \mathrm{n} / \mathrm{s}$ into $4 \pi$ was used. For the first run, the interval distribution was analyzed, and for the second, the events per unit time.

Run 1: With the source about 1 meter from the cell the apparatus was run at constant negative pressure until 245 cavitation events had occurred; the times were automatically recorded on a strip chart. On account of the dead time (1.31 s) 24 short intervals were missed. The total of 268 intervals were arranged in 8 groups and analyzed as shown in table 2 using the $\chi^{2}$ test [Evans, 1955, ch. 27]. No statistically significant departure from an exponential distribution of interval lengths was observed and hence we may regard the cavitation events as occurring individually and collectively at random.

TABLE 2. Test of randomness (interval distribution), in isopropanol

\begin{tabular}{|c|c|c|c|c|c|}
\hline Class & $l_{1}{ }^{\mathrm{a}}$ & $l_{2 .}$ & $x_{0}{ }^{b}$ & $x_{e}{ }^{c}$ & $\left(\frac{x_{0}-x_{e}}{x_{e}}\right)^{2}$ \\
\hline $\begin{array}{l}1 \\
2 \\
3 \\
4 \\
5 \\
6 \\
7 \\
8\end{array}$ & $\begin{array}{c}m m \\
0 \\
1 \\
2 \\
4 \\
6 \\
8 \\
10 \\
13\end{array}$ & $\begin{array}{c}m m \\
1 \\
2 \\
4 \\
6 \\
8 \\
10 \\
13 \\
24\end{array}$ & $\begin{array}{r}57 \\
53 \\
59 \\
35 \\
27 \\
17 \\
9 \\
11 \\
\\
\sum 268\end{array}$ & $\begin{array}{r}57.6 \\
45.3 \\
63.2 \\
39.0 \\
24.1 \\
14.8 \\
12.3 \\
11.4 \\
\\
267.7\end{array}$ & $\begin{array}{r}.006 \\
1.309 \\
0.279 \\
.410 \\
.349 \\
.327 \\
.885 \\
.014 \\
\\
3.579\end{array}$ \\
\hline & & \multicolumn{2}{|c|}{$\begin{aligned} \chi^{2} & =3.58 \\
F & =6 \\
P & =0.73\end{aligned}$} & & \\
\hline
\end{tabular}

a Time measured by length $l$ on chart.

${ }^{\mathrm{b}}$ Observed number of intervals of length $l$ such that $l_{1} \leqslant l<l_{2}$.

" Expected number of intervals from $x_{e}=268\left[\exp \left(-0.242 l_{1}\right)\right.$ $-\exp \left(-0.242 l_{2 .}\right)$ ]; $0.242=$ mean number of events $/ \mathrm{mm}$.

Run 2: With the source at about 0.6 meter from the cell, the negative pressure was adjusted so that about 14 events occurred per minute (gross). Events were counted during 23 6-min runs. After adjustment for dead time (1.44 s/event) the counts were subjected to $\chi^{2}$ analysis. The results were

$$
\begin{aligned}
& \chi^{2}=24.6 \\
& F=22 \\
& P=0.30 .
\end{aligned}
$$

The average count rate was $21.5 / \mathrm{min}$ with a standard deviation from residuals of $6.1 / \mathrm{min}$ and an expected standard deviation of $(21.5)^{1 / 2}=4.6 / \mathrm{min}$. The conclusion is the same as for run 1.

The inverse-square test is more difficult to do, especially in a small room, because of the reflection of neutrons from the sides and the furniture. Using the same equipment and conditions as before, some tests were made on isopropanol and more on freon 113 [Greenspan and Tschiegg, 1966a]. We indicate the results for the freon 113. At a fixed negative pressure 3 runs were made at each of the distances 0.91 , $1.09,1.28,1.52,1.83$, and 2.11 meter. The products, counts/unit time by square of distance, were averaged for the 18 runs and used to calculate the expected count for each run. The $\chi^{2}$ test gave $P=0.18$. The experiment was repeated at a pressure amplitude $2 \mathrm{~dB}$ higher with the result $P=0.22$. It thus appears that the cavitation rate at fixed pressure is proportional to neutron flux. West and Howlett [1967] have performed a similar experiment on tetrachloroethylene using a Po-Be source. They feel the inverse-square law to have been verified within the experimental error.

\section{b. Threshold}

As a preliminary to the definition of a neutron threshold we consider how the cavitation rate varies with the negative pressure, $-p$. Lieberman [1959] introduced the concept of "effective sensitive volume," $V_{e}$; his argument may be paraphrased as follows. In the hypothetical case of a liquid populated by identical nuclei, upon each of which cavitation occurs whenever it is in a region in which the negative pressure, $-p$, exceeds a fixed value $T$, called the threshold, the "sensitive volume," $V_{s}$, is that volume in which, everywhere, $-p>T$. During each period of the pressure oscillation, there is a "sensitive time," $t_{s}$, during which $-p>T$; this time varies with position in $V_{s}$, being greater the greater the pressure amplitude and zero at the boundary of $V_{s}$. Then he defined

$$
V_{e}=\int_{V_{s}} \frac{t_{s}}{\tau} d V s
$$

( $\tau$ is the period), to which the cavitation rate might be expected to be proportional under the assumed conditions. Lieberman calculated, by numerical integration, $V_{e}$ as a function of $-p / T$ for the case of a spherical resonator (sound pressure amplitude varies like $\sin k r / k r) .{ }^{10}$

His curve, which we have extended downward, is shown in figure 9. Shown also are our results ${ }^{11}$ in freon 113 for the conditions given in table 3 . It is seen that the cavitation rate increases more rapidly with negative pressure than does the effective volume. From a similar experimental result Lieberman was able to draw various conclusions about the action of

\footnotetext{
10 Rough calculations show that the shape of the curve is nearly the same for other pressure distributions,

1 The results of Lieberman $|1959|$. in pentane, are qualitatively the same; those of West and Howlett |1967|, in tetrachloroethylene, very different.
} 


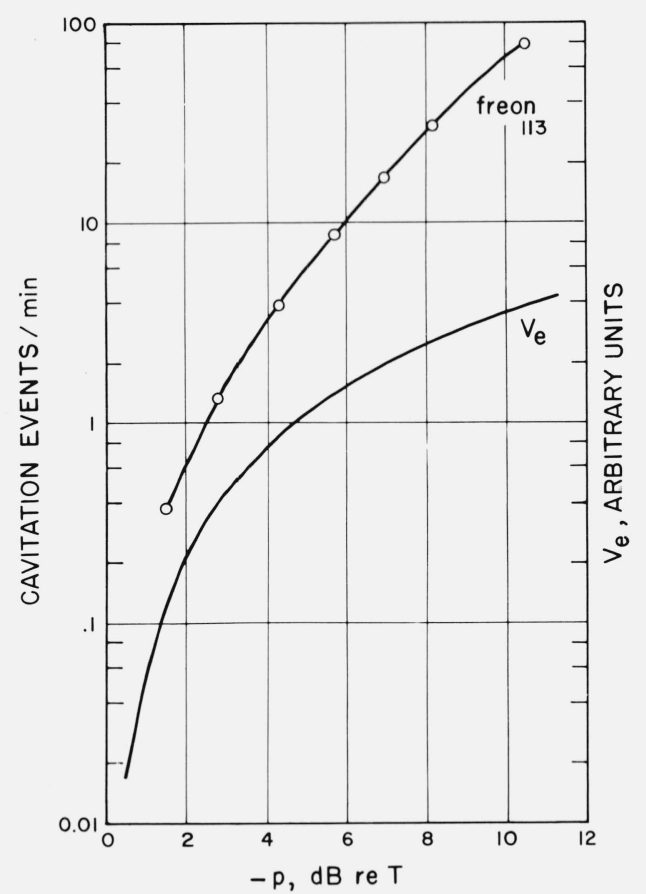

Figure 9. Cavitation rate versus negative pressure for freon 11.3; neutron irradiated.

See table 3 for conditions. Lieberman's effective sensitive volume is shown in arbitrar unit.

neutrons in nucleating cavitation. These matters are beyond the scope of this paper; we only remark that we have made some rough measurements using nearly monoergic neutrons which support Lieberman's ideas.

Part of the freon 113 data in figure 9 is shown again in figure 10 together with data on methanol, isopropanol, and ether. The ordinates have been normalized as shown in table 3 , which also gives the test conditions. Although the actual cavitation rate spans the range 0.37 per min (in freon 113) to 680 per min (in methanol), the points fall reasonably well on a universal curve although systematic differences from liquid to liquid are unmistakable (compare isopropanol with ether). The result is consistent with the following:

(1) the cavitations are "single-particle" events;

(2) the range for $-p / \tau$, about $6 \mathrm{~dB}$, is too small to show differences between the neutron spectra of $\mathrm{Am}-\mathrm{Be}$ and $\mathrm{Pu}-\mathrm{Be}$ at their upper ends;

(3) over the same range, geometrical effects $\left(V_{e}\right)$ as between cylinders and cones are not large.

TABLE 3. Test conditions for figures 9 and 10

\begin{tabular}{|c|c|c|c|c|}
\hline Liquid & $\begin{array}{c}\text { Freon } \\
113\end{array}$ & $\begin{array}{l}\text { Methyl } \\
\text { alcohol }\end{array}$ & $\begin{array}{l}\text { Isopropyl } \\
\text { alcohol }\end{array}$ & $\begin{array}{l}\text { Ethyl } \\
\text { ether }\end{array}$ \\
\hline Source & $\mathrm{Am}-\mathrm{Be}$ & $\mathrm{Pu}-\mathrm{Be}$ & $\mathrm{Pu}-\mathrm{Be}$ & $\mathrm{Am} \cdot \mathrm{Be}$ \\
\hline 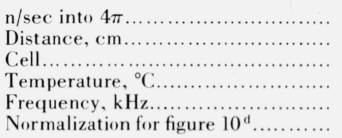 & $\begin{array}{c}1.6 \times 10^{7} \\
91 \\
(\mathrm{~b}) \\
31.5 \\
34.7 \\
0.07\end{array}$ & $\begin{array}{l}1.5 \times 10^{7} \\
\left({ }^{a}\right) \\
\left({ }^{c}\right) \\
25.6 \\
37.4 \\
10\end{array}$ & $\begin{array}{c}1.5 \times 10^{7} \\
91 \\
(\mathrm{~b}) \\
31.5 \\
39.5 \\
0.37\end{array}$ & $\begin{array}{c}1.6 \times 10^{7} \\
25 \\
\left({ }^{c}\right) \\
28.5 \\
44.8 \\
0.47\end{array}$ \\
\hline
\end{tabular}

"Source adjacent to cell.

" Ceramic cylinder in $(3,0,1)$ mode, see figure $1.75 \mathrm{~cm}$ OD by $100 \mathrm{~cm}$ high

"Conical flask, mode unknown, see figure $3.125 \mathrm{ml}$

"Cavitations/min corresponding to the ordinate "l.

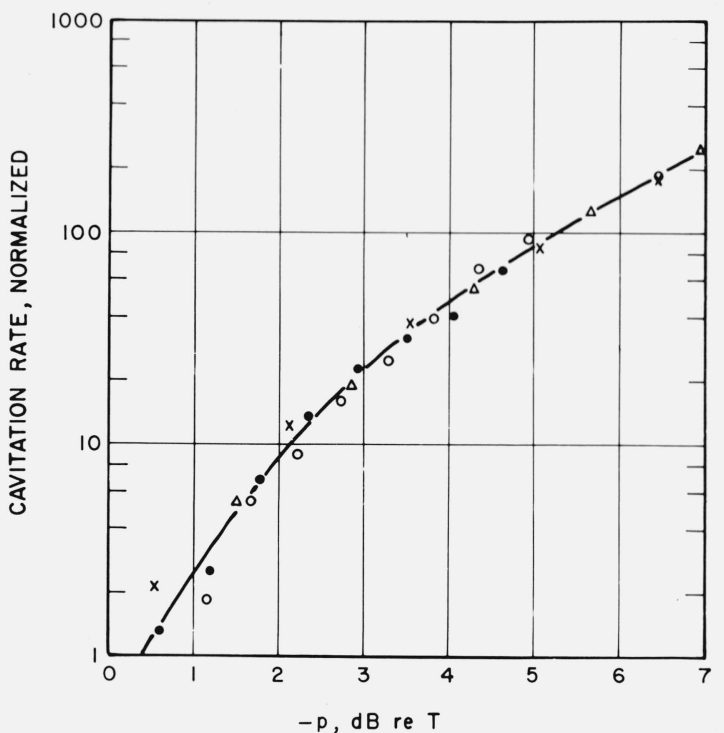

FIGURE 10. Cavitation rate versus negative pressure for four liquids; neutron irradiated.

See table 3 for conditions. The ordinate "l" corresponds to $0.07 / \mathrm{min}$ for freon $113(\triangle)$, to $10 / \mathrm{min}$ for methyl alcohol $(\bullet)$, to $0.37 / \mathrm{min}$ for isopropyl alcohol $(O)$, and to $0.47 / \mathrm{min}$ for diethyl ether $(x)$.

As can be seen from figures 9 and 10 , if a neutron source be placed adjacent to the cell, the operator can find a value of the electrical readout below which cavitations occur rarely and above which they occur at a rate of several per minute. The procedure is subjective and the reading obtained depends somewhat on the neutron output of the source and on the effective sensitive volume in the liquid, but nevertheless it can in most cases be reproduced to within \pm 1 $\mathrm{dB}$ at worst and often to within $\pm 0.2 \mathrm{~dB}$. Such readings are arbitrarily taken to correspond to thresholds, and from a series of them taken at various overpressures, a "neutron threshold" corresponding to the particular source is gotten as described in section $2.4 \mathrm{~b}$. The main advantage of the procedure is its speed and ease. It is desirable that our thresholds be comparable to those obtained by others. Unfortunately very few thresholds for $(\alpha, n)$ sources have been measured. For $n$-pentane, Lieberman [1959] got 2.1 bars in the room temperature region; we got about 1.3. For acetone his values average to 5.5; ours is 4.8 . We have a private communication from C. West [Harwell] giving $6.5 \pm 1.2$ bar in tetrachloroethylene, not far from our 7.8. These are all we can find, and although the agreement seems marginal, those familiar with cavitation data may find it rather good. Both authors cited worked at about $20 \mathrm{kHz}$, and our results are for 28 and $35 \mathrm{kHz}$ in $n$-pentane, for $40 \mathrm{kHz}$ in acetone, and for $49 \mathrm{kHz}$ in $\mathrm{C}_{2} \mathrm{Cl}_{4}$. We have made this comparison because there is some evidence that the neutron threshold depends little on frequency in the range $20-60 \mathrm{kHz}$, at least; nevertheless this point requires investigation. 
TABlE 4. Some neutron thresholds, $\mathrm{Pu}$-Be source

\begin{tabular}{|c|c|c|c|c|c|}
\hline Liquid & \multirow{2}{*}{$\begin{array}{c}\begin{array}{c}\text { Normal } \\
\text { boiling } \\
\text { point }\end{array} \\
{ }^{\circ} \mathrm{C}\end{array}$} & \multirow{2}{*}{$\begin{array}{c}\text { Temp. } \\
{ }^{\circ} \mathrm{C}\end{array}$} & \multirow{2}{*}{$\begin{array}{c}\begin{array}{c}\text { Fre- } \\
\text { quency }\end{array} \\
k H z\end{array}$} & \multirow{2}{*}{$\begin{array}{c}\text { Threshold } \\
\text { (absolute) }\end{array}$} & \multirow[t]{2}{*}{ Notes } \\
\hline \multirow[b]{3}{*}{ 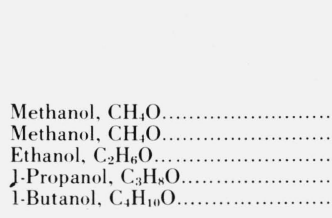 } & & & & & \\
\hline & \multicolumn{4}{|c|}{ Part 1} & \\
\hline & $\begin{array}{r}78.4 \\
97.8 \\
117.5\end{array}$ & $\begin{array}{l}27 \\
27 \\
28 \\
27 \\
26\end{array}$ & $\begin{array}{l}39 \\
52 \\
42 \\
56 \\
41\end{array}$ & $\begin{array}{r}5.0 \\
5.1 \\
6.7 \\
14.4 \\
15.0\end{array}$ & $\begin{array}{l}\text { (a) } \\
\text { (b) } \\
\text { (a) } \\
\text { (b) } \\
\text { (c) }\end{array}$ \\
\hline \multirow[t]{2}{*}{ 2-Propanol, $\mathrm{C}_{3} \mathrm{H}_{*} \mathrm{O} \ldots$} & 82.5 & 29 & 40 & 8.6 & $(a, d)$ \\
\hline & \multicolumn{4}{|c|}{ Part 2} & \\
\hline \multirow[t]{2}{*}{ 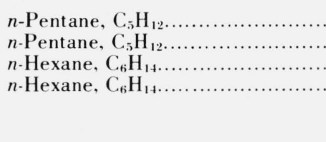 } & 36.1 & $\begin{array}{l}24.5 \\
26.5 \\
26.5 \\
26.9\end{array}$ & $\begin{array}{l}28 \\
35 \\
41 \\
35\end{array}$ & $\begin{array}{l}1.5 \\
1.0 \\
2.4 \\
2.5\end{array}$ & $\begin{array}{l}(\mathrm{c}) \\
(\mathrm{c}) \\
(\mathrm{c}) \\
(\mathrm{c})\end{array}$ \\
\hline & \multicolumn{4}{|c|}{ Part 3} & \\
\hline $\begin{array}{l}\text { Diethylether, } \mathrm{C}_{4} \mathrm{H}_{10} \mathrm{O} \ldots \ldots \ldots \ldots \ldots \ldots \ldots \ldots \ldots \ldots \ldots \\
\text { Diethylether, } \mathrm{C}_{4} \mathrm{H}_{10} \mathrm{O} \ldots \ldots \ldots \ldots \ldots \ldots\end{array}$ & 34.6 & $\begin{array}{l}24.8 \\
27.4\end{array}$ & $\begin{array}{l}55 \\
54\end{array}$ & $\begin{array}{l}1.9 \\
1.4\end{array}$ & $\begin{array}{l}\text { (b) } \\
\text { (b) }\end{array}$ \\
\hline $\begin{array}{l}\text { Freon } 113, \mathrm{C}_{2} \mathrm{Cl}_{3} \mathrm{~F}_{3} \ldots \ldots \ldots \ldots \ldots \ldots \\
\text { Freon } 113, \mathrm{C}_{2} \mathrm{Cl}_{3} \mathrm{~F}_{3} \ldots \ldots \ldots \ldots \ldots \ldots \ldots \\
\text { Freon } 113, \mathrm{C}_{2} \mathrm{Cl}_{3} \mathrm{~F}_{3} \ldots \ldots \ldots \ldots \ldots \ldots \ldots \ldots \ldots \ldots \ldots \ldots \ldots \ldots \ldots \ldots \ldots \ldots \ldots \ldots \\
\text { Freon } 113, \mathrm{C}_{2} \mathrm{Cl}_{3} \mathrm{~F}_{3} \ldots \ldots \ldots \ldots \ldots \ldots \ldots \\
\text { Freon } 113, \mathrm{C}_{2} \mathrm{Cl}_{3} \mathrm{~F}_{3} \ldots \ldots \ldots \ldots \ldots \ldots \ldots\end{array}$ & $\begin{array}{l}47.6 \\
\ldots \ldots \ldots\end{array}$ & $\begin{array}{r}0 \\
26 \\
28 \\
29 \\
29\end{array}$ & $\begin{array}{l}39 \\
35 \\
35 \\
35 \\
45\end{array}$ & $\begin{array}{l}3.8 \\
1.8 \\
2.0 \\
1.6 \\
1.8\end{array}$ & $\begin{array}{l}\text { (e) } \\
\text { (e) } \\
\text { (e) } \\
\text { (e) } \\
\text { (f) }\end{array}$ \\
\hline \multirow[t]{2}{*}{$\begin{array}{l}\text { Freon } 11, \mathrm{CCl}_{3} \mathrm{~F} \ldots \ldots \ldots \ldots \ldots \ldots \ldots \ldots \ldots \ldots \ldots \ldots \ldots \ldots \ldots \ldots \ldots \ldots \ldots \ldots \ldots \\
\text { Freon } 11, \mathrm{CCl}_{3} \mathrm{~F} \ldots \ldots \ldots \ldots \ldots \ldots\end{array}$} & 23.7 & $\begin{array}{l}26.5 \\
27.0\end{array}$ & $\begin{array}{l}44 \\
45\end{array}$ & $\begin{array}{l}1.7 \\
1.9\end{array}$ & $\begin{array}{l}\text { (g) } \\
\text { (g) }\end{array}$ \\
\hline & \multicolumn{4}{|c|}{ Part 4} & \\
\hline $\begin{array}{l}\text { Ethyl bromide, } \mathrm{C}_{2} \mathrm{H}_{5} \mathrm{Br} \ldots \ldots \ldots \ldots \\
\text { Ethyl bromide, } \mathrm{C}_{2} \mathrm{H}_{5} \mathrm{Br} \ldots \ldots \ldots \ldots\end{array}$ & 38.4 & $\begin{array}{l}30 \\
31\end{array}$ & $\begin{array}{l}47 \\
36\end{array}$ & $\begin{array}{l}3.1 \\
3.1\end{array}$ & $\begin{array}{l}\text { (c) } \\
\text { (c) }\end{array}$ \\
\hline $\begin{array}{l}\text { Carbon tetrachloride, } \mathrm{CCl}_{4} \ldots \ldots \ldots \ldots \\
\text { Trichloroethylene, } \mathrm{C}_{2} \mathrm{HCl}_{3} \ldots \ldots \ldots \ldots \\
\text { Tetrachloroethylene, } \mathrm{C}_{2} \mathrm{Cl}_{4} \ldots \ldots \ldots \ldots\end{array}$ & $\begin{array}{r}76.7 \\
86.7 \\
120.8\end{array}$ & $\begin{array}{l}29 \\
30 \\
27\end{array}$ & $\begin{array}{l}50 \\
48 \\
49\end{array}$ & $\begin{array}{l}4.9 \\
4.5 \\
7.5\end{array}$ & $\begin{array}{l}\text { (g) } \\
\text { (g) } \\
\text { (b) }\end{array}$ \\
\hline Tetrachloroethylene, $\mathrm{C}_{2} \mathrm{Cl}_{4} \ldots \ldots \ldots \ldots$ & \multicolumn{4}{|c|}{ Part 5} & \\
\hline $\begin{array}{l}\text { Methylene chloride, } \mathrm{CH}_{2} \mathrm{Cl}_{2} \ldots \ldots \ldots \\
\text { Methylene chloride, } \mathrm{CH}_{2} \mathrm{Cl}_{2} \ldots \ldots \ldots \\
\text { Methylene chloride, } \mathrm{CH}_{2} \mathrm{Cl}_{2} \ldots \ldots \ldots \\
\text { Methylene chloride, } \mathrm{CH}_{2} \mathrm{Cl}_{2} \ldots \ldots \ldots\end{array}$ & 39.5 & $\begin{array}{l}26.3 \\
27.2 \\
27.4 \\
28.7\end{array}$ & $\begin{array}{l}35 \\
43 \\
29 \\
53\end{array}$ & $\begin{array}{l}3.0 \\
5.1 \\
3.3 \\
4.5\end{array}$ & $\begin{array}{l}(\mathrm{c}) \\
(\mathrm{c}) \\
(\mathrm{c}) \\
(\mathrm{c})\end{array}$ \\
\hline
\end{tabular}

a In $\mathrm{Ba} \mathrm{TiO}_{3}$ cylinder, $7.5 \mathrm{~cm} \mathrm{D} \mathrm{by} 7.5 \mathrm{~cm}$ high, $(3,0,1)$-mode. See figure l(a). b $300 \mathrm{ml}$ conical flask, mode unknown. See figure 3 .

c $125 \mathrm{ml}$ conical flask, mode unknown. See figure 3 .

d 2-propanol is out of place, but is shown for companion.

e In lead zirconate-titanate cylinder, $7.5 \mathrm{~cm} \mathrm{OD}$ by $7.5 \mathrm{~cm}$ high, $(3,0,1)$-mode. See figure l(b).

'As (e), but mode unknown.

${ }^{*} 250 \mathrm{ml}$ conical flask, mode unknown. See figure 3 .

Some neutron thresholds obtained by the method described are given in table 4 . These are intended to be illustrative only, but some possible trends emerge.

1. There is some evidence for frequency independence (part 1, methanol; part 2, freon 113; part 4, ethyl bromide).

2. In a homologous series, the neutron threshold increases as the series is ascended. Part 1 lists 4 normal alcohols and part 2, two normal alkanes.

3 . In general the threshold decreases as the temperature increases. The dependence is stronger for temperatures closer to the normal boiling point. See parts 2 and 3. To interpret the results for freon 113 (part 3) this way we have to suppose that these thresholds are subject to an error of at least 0.2 bar.

4. One gets the impression that, other things being equal, low boiling liquids have a lower threshold than high. However, freon 11 and freon 113 contain the same elements, and have approximately the same
TABLE 5. Neutron threshold versus neutron energy. $\mathrm{T}=29^{\circ} \mathrm{C}, \mathrm{F}=44-52 \mathrm{kHz}$.

\begin{tabular}{l|c|c|c}
\hline \multirow{2}{*}{ Neutron } & \multicolumn{3}{|c}{ Threshold, bar } \\
\hline \multicolumn{1}{c|}{$\mathrm{MeV}$} & Freon 113 & Methanol & Ethanol \\
& & & \\
& & 10.4 & 13.4 \\
Pu-Be $\left(10.4 ?{ }^{2}\left[D(d, n) \mathrm{He}^{3}\right]\right.$ & 1.8 & 5.0 & 6.7 \\
$14[T(d, \alpha) n]$ & 0.7 & 2.4 & 4.0 \\
\hline
\end{tabular}

density, thermal expansion coefficient, surface tension, specific heat, and latent heat (per mole); ${ }^{12}$ yet they have about the same threshold at (say) $27{ }^{\circ} \mathrm{C}$ although the vapor pressure of freon 11 at this temperature is almost twice that of freon 113 .

5. Note how the effects of atomic composition can be separated from those of gross physical properties. Examples are the isomers 1-propanol and 2propanol in part 1 , and the pair 1 -butanol in part 1 and diethyl ether in part 2 , both of which are $\mathrm{C}_{4} \mathrm{H}_{10} \mathrm{O}$.

6. Part 5 is included to show a liquid, methylene chloride, in which the neutron thresholds as measured vary irregularly with frequency even though the original data look good. We suspect that the sensitive volumes were so small in relation to the available neutron flux, and varied so much from frequency to frequency, that the measured "thresholds" are not comparable. The neutron thresholds as defined would be much more determinate if the source were either larger, more nearly monoergic, or both.

Some miscellaneous results are given in part 4.

\section{c. Threshold Versus Neutron Energy}

We have made some preliminary measurements of threshold as a function of neutron energy. In table 5, it is tentatively presumed that what are being seen in the $\mathrm{Pu}$-Be source are the neutrons of maximum energy. The 2.5 MeV neutrons are from the $\mathrm{D}-\mathrm{D}$, and the 14 $\mathrm{MeV}$, from the $\mathrm{D}-\mathrm{T}$, reactions. ${ }^{13}$ The results are probably only rough because the neutron generator was operated near its minimum output where the flux is both unknown and irregular. The implications of these results with respect to a principle for neutron spectrometry is obvious.

\subsection{Alpha-Recoil Induced Cavitation}

An $\alpha$-emitter dissolved in a liquid provides cavitation nuclei in any concentration desired [Greenspan and Tschiegg, $1966 \mathrm{a}, \mathrm{b}]$. As Riepe and Hahn [1961] who worked with $\alpha$-emitters in a bubble chamber have pointed out, the heavy recoil nucleus, although it

\footnotetext{
${ }^{12}$ The properties listed are those which are considered significant in various theories.
The viscosity has been omitted, but this is larger for freon 113 than for freon 11 , which would be expected to further increase the threshold for 113 compared to that for 11 .

${ }^{13} \mathrm{We}$ are indebted to Frank Sentfle and his co-workers of the U.S. Geological Survey for making available and operating the neutron generator.
} 
carried only about 2 percent of the total energy, is the responsible agent, because of its very small range relative to that of the $\alpha$-particle. Indeed the range is in most cases so small that all of the energy is deposited in the immediate neighborhood of the impending cavitation, so that if all disintegrations were of the same energy all cavitation nuclei would correspond to the same threshold. In this case the function, cavitation rate versus negative pressure, would be expected to be nearly the same as Lieberman's effective sensilive volume function already discussed and shown in figure 9.

We have made measurements on methanol and on diethyl ether; the $\alpha$-emitter was ordinary reagentgrade thorium nitrate at a concentration of $3 \mathrm{~g} / \mathrm{l}$, which corresponds to about 300 disintegrations per minute $(\mathrm{dpm})$ for the parent and each daughter in equilibrium with it. The age of the salt is unknown, but rough $\alpha$-range measurements in air show that a considerable amount of the last $\alpha$-emitter in the chain (ThC') is present. The ThC' has the highest $\alpha$-disintegration energy, $8.95 \mathrm{MeV}$, in the chain, and if in equilibrium would yield $200 \alpha$ 's/min on account of branching in the decay of its parent, ThC, which would

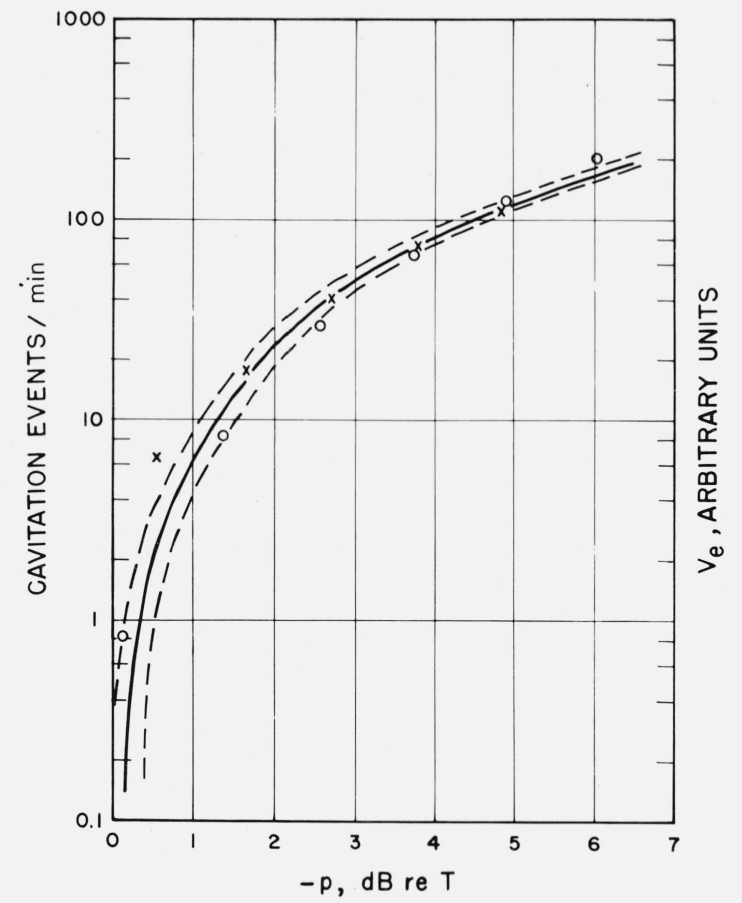

Figure 11. Cavitation rate versus negative pressure for methanol and ethyl ether; $\alpha$-disintegrations.

$\times$ methanol at $26^{\circ} \mathrm{C}$. in $125 \mathrm{ml}$ conical flask (see fig. 3 ). $f=37 \mathrm{kHz}$.

0 ethyl ether at $28^{\circ} \mathrm{C}$, in similar cell, (see fig. 3) $f=45 \mathrm{kHz}$

The solid line is Lieberman's effective sensitive volume curve.

The dashed lines show it shifted $\pm 0.2 \mathrm{~dB}$. provide about $100 \alpha$ 's/min of energy $6.05 \mathrm{MeV}$. Five other $\alpha$-emitters are also present; their $\alpha$ energies range from 4.00 to $6.77 \mathrm{MeV}$.

The results are shown in figure 11 superimposed on Lieberman's $V_{e}$ curve in such a way as to give the best fit by eye. The dashed curves are drawn to show the errors in the cavitation rates produced by a $\pm 0.2 \mathrm{~dB}$ drift in the apparatus. The methanol results show good agreement as would be expected if only the ThC' disintegrations were effective and the ether results indicate that the lower-energy disintegrations come into play as the negative pressure increases. It is hardly likely that one situation prevails for methanol and the other for ether, so the results must be considered as preliminary to further work with single-isotope solutes. The " $\alpha$-thresholds" were 11.0 bars for methanol and 4.0 bars for ether.

\subsection{Fission}

Messinò, et al. [1963], reported that the cavitation threshold of water was lowered from 1.6 to 0.55 bar by the addition of 5 percent uranyl nitrate, and ascribed the result to fission of the $\mathrm{U}^{235}$ fraction $(0.7 \%)$ by cosmic neutrons thermalized by the water. In spite of the low cosmic-neutron flux the hypothesis is consistent with the authors' view that the cavitation nuclei have a long lifetime, although it is not clear that the authors gave due consideration to the competing sources of spontaneous fission in $U^{238}$ and of the laboratory neutron source (see section 3.3).

We have observed fast fission in solutions of thorium nitrate in isopropanol and in methanol, at thresholds not very well defined, but about $10 \mathrm{~dB}$ below the neutron threshold. The spontaneous fission rate of $\mathrm{Th}^{232}$ is about $0.15 / \mathrm{g} \mathrm{hr}$ and that from cosmic neutrons $<0.003 / \mathrm{g}$ hr [Segrè, 1952].

A solution of natural uranyl nitrate in clean water exposed to neutrons from our $\mathrm{Pu}$-Be source cavitates at negative pressures in the range 10 to 20 bars. The events appear to be as abrupt as those induced by neutrons or $\alpha$-recoils and cavitation ceases immediately as the source is encased. No such effect is observed at much higher stresses if other heavy metal salts are substituted, and without doubt both thermal and fast fission are observed in the natural uranium, for which the fission cross sections are about 4 and 0.5 barns, respectively.

Uranium in methanol exhibits some peculiar features. Many of the events leave large bubbles which are trapped in the pressure nodes, and which persist until the sound field is removed, even though the liquid has been first degassed. It is difficult to say anything about the effect of cosmic neutrons on the fission, because we can remove our encased source $(23 \mathrm{~cm}$ of paraffin) only to about 40 meters from the cell. At this distance the output of the shielded source is still comparable to the cosmic flux. Only a few fissions per hour are observed. 


\section{Remarks}

We have described several types of apparatus and procedures for their use which allow the acoustic cavitation properties of liquids to be determined with much greater reproducibility than hitherto attained. They are susceptible to further improvement, so that eventually it should be possible to make measurements as precise as the statistical nature of cavitation properties, and the imperfect characterization of the test liquids, permit.

Contaminants can be removed, with some ease or with considerable difficulty, depending on the nature of the liquid, so that over a range of (negative) pressure levels cavitations occur only when nucleated by certain ionizing radiations. The cavitations are always single-particle events, at least under the conditions of our experiments. The results presented are mostly for illustration: more systematic investigations, which we hope refinements in the apparatus will make possible, will yield a body of empirical data which can be expected to support some existing theories of the process and cast doubt upon others, and perhaps to point the way to their modification. Presumably the theories of ultrasonic cavitation, of the bubble chamber, and of the static strength of liquids, are interrelated, and some features of these processes are doubtless shared by hydraulic cavitation as well.

Ionizing particles provide reproducible nuclei for studies of ultrasonic cavitation per se, but the possibility of using radiation-induced cavitation in nuclear instrumentation has intrigued many, beginning with Hughes [1960]. Hahn and Peacock [1963] proposed a neutron detector discussed at greater length by Bertolotti, et al. [1965]; more definitive experiments were performed by West [1965]. Our work extends these notions to a wide variety of liquids and opens up the possible development of a neutron spectrometer.

\section{References}

Ballantine, S. (1932) J. Acoust. Soc. Am. 3, 319-360.

Barger, James E. (1964) Thresholds of Acoustic Cavitation, Technical Memorandum No. 57, Acoustics Research Laboratory, Harvard University, ONR Contract Nonr 1866(24).

Beranek, Leo L. (1949) Acoustic Measurements (Wiley \& Sons, Inc., New York, N.Y.).

Bertolotti, M., Sette, D. and Wanderlingh F. (1965) Nucl. Inst. and Meth. 35, 109-112.

Davies, Philip W. (1962) Chapter 3 of Physical Techniques in Biological Research, Vol. IV, (Academic Press).

Evans, R. D. (1955) The Atomic Nucleus (McGraw-Hill Book Co., New York, N.Y.).

Finch, R. D. (1964) J. Acoust. Soc. Am. 36, 2287-2292.

Flynn, H. G. (1964) Chapter 9 of Physical Acoustics, Vol. I, Part B, W. P. Mason, Ed. (Academic Press, New York).

Galloway, W. J. (1954) J. Acoust. Soc. Am. 26, 849-857.

Greenspan, Martin and Tschiegg, Carl E. (1966a) J. Acoust. Soc. Am. 39, 1236 (abstr).

Greenspan, Martin and Tschiegg, Carl E. (1966b) J. Acoust. Soc. Am. 40, 1239 (abstr).

Hahn, B. and Peacock, R. N. (1963) Nuclear Inst. and Methods 20, $133-134$.

Lieberman, D. (1959) Phys. Fluids 2, 466-468 (additional details in his thesis "Radiation-Induced Cavitation", Tech. Report No. XII, Project NR 014-302 of U.S. Office of Naval Research. Univ. of Calif., Los Angeles).

Leonard, R. W. (1946) J. Acoust. Soc. Am. 18, 252.

Messinò, C. D., Sette, D. and Wanderlingh, F. (1963) J. Acoust. Soc. Am. 35. 1575-1583.

Messinò, C. D., Sette, D. and Wanderlingh, F. (1967) J. Acoust. Soc. Am. 41, 573-583.

Owen, R. E. (1967) General Radio Experimenter 41, No. 2, 3-11.

Riepe, G. and Hahn, B. (1961) Helv. Phys. Acta. 34, 865-892.

Segrè, E. (1952) Phys. Rev. 86, 21.

Sette, D. and Wanderlingh, F. (1962) Phys. Rev. 125, 409-417.

Sirotyuk, M. G. (1962) Soviet Phys-Acoust. 8, 165-169.

Strasberg, M. (1959) J. Acoust. Soc. Am. 31, 163-176.

Tajima, Eizo; Adachi, Minoru; Doke, Tadayoshi; Kubota, Shinzou; and Tsukuda, Masahiro (1967) J. Phys. Soc. Japan, 22, 355-360.

Watt, D. E. (1967) Health Physics 13, 501-507.

West, C. (1965) Nucl. Inst. and Meth. 33, 361-362.

West, C. and Howlett, R. (1967) Some Experiments on Ultrasonic Cavitation Using a Pulsed Neutron Source. U K Atomic Energy Authority Research Group Memo AERE-M1880.

Willard, G. W. (1953) J. Acoust. Soc. Am. 25, 669-686.

Paper 71C4-261) 